\title{
Síntomas Hipoglicémicos en la Enfermedad de Addison
}

\author{
Dr. Tomás Mesa L. ${ }^{1}$, Dra. Raquel Burrows A. ${ }^{2}$, Dr. Santiago Muzzo B. ${ }^{3}$
}

\author{
Hipoglicemic symptoms in Addison's disease
}

\begin{abstract}
Addison's disease in childhood is a rarc illness. A 13 ycars old boy, with Addison's disease is presented. His diagnosis, was suspected by hipoglicemic crisis and neuropsychiatric alterations. The importance of knowing the variety of initial simptoms and of and early diagnosis, is discussed. The advantages of the fluorated glucocorticoid as replacement mineralocorticoid therapy is analized.
\end{abstract}

La enfermedad de Addison en niños es de baja frecuencia. En 1946, Jaudon ${ }^{1}$ recopiló de la literatura mundial 59 casos en menores de 15 aflos, de los cuales un $59 \%$ eran hombres. Un $80 \%$ tenia entre 11 y 15 años de edad y sólo el $5 \%$ eran menores de 5 años. Desde 1878, año en que Francisco Mesa ${ }^{2-3}$ diagnosticó el primer caso de Enfermedad de Addison en Chile, a 1899, se habian descrito 12 casos, de los cuales solamente uno era menor de 15 años. Antes de 1930, la Tuberculosis causaba el $70 \%$ de las enfermedades de Addison, posteriormente esta cifra bajó a menos del $50 \%$ y con la introducción de las drogas antituberculosas, la proporción disminuyó enormemente 4 . Actualmente la etiologia autoinmune de Addison pasó a ser porcentualmente la causa más frecuente en países desarrollados. Blizzard y cols. ${ }^{5}$, describen que 71 pacientes con Enfermedad de Addison, un 50\% presentaron anticuerpos anticorteza adrenal circulantes. Entre las enfermedades asociadas al Addison ${ }^{1}$, se han descrito, la Histoplasmosis, Reticuloendoteliosis, Amiloidosis, Hipoparatiroidismo, Hipotiroidismo 5 y Diabetes Mellitus entre otras ${ }^{6-7}$. Dentro de la sintomato. logía de esta enfermedad, el compromiso del estado general (astenia, anorexia, baja de peso $y$ debilidad), la pigmentación generalizada de piel y mucosas, los síntomas gastrointestinales (vómito, diarrea y dolor abdominal generalizado), se presentan en más del $85 \%$ de los casos. Convulsiones y coma brusco en un $32 \%$ y convulsiones recurrentes que podrian ser interpretadas como de origen hipoglicémico, sólo en un 13\%1. La disminución de los glucocorticoides de esta enfermedad, predispondría a la hipoglicemia ${ }^{B}$. En el control de esta enfermedad, es necesario tratar la causa $y$ reemplazar en forma mantenida las hormonas deficitarias.

Actualmente se usa en la terapia de reemplazo

\footnotetext{
1 Servicio de Pediatría, Hospital Sótero del Río.

2 Departamento de Pediatría, Universidad Católica.

3 Unidad de Endocrinología del Instituto de Nutrición y

Tecnología de los Alimentos, Universidad de Chile.
}

de mineralocorticoides un glucocorticoide fluorado, el 9- $\alpha_{-}$-fluorohidrocortisona, que tiene alta capacidad retenedora de sodio y es de fácil administración por vía oral ${ }^{4-7-9}$.

Se presenta el caso de un niño con enfermedad de Addison, dada su rareza, para discutir los sintomas y actualizar el tratamiento.

\section{CASO CLINICO}

Paciente de 13 años de sexo masculino. Antecedentes de prematurez y recambio sanguíneo por hiperbilirrubinemia secundaria a incompatibilidad $\mathrm{Rh}$. Se hospitaliza por presentar debilidad, vómitos frecuentes, progresivo compromiso de conciencia, sin legar al coma. Un año antes de la admisión había iniciado cambios progresivos de carácter, con apatía y disminución del rendimiento escolar. Dos meses antes de su ingreso, se le practicó una circunscición y orquipexia por criptorquidea derecha, pocos dís después se rehospitalizó por compromiso de conciencia, deposiciones líquidas, fiebre y glicemia en ayunas de $46 \mathrm{mg} \%$, lo que se interpretó como una enfermedad de etiología probablemente virai. Sin embargo, como continuaba con compromiso de conciencia, se solicitó un EEG que reveló un foco temporal por lo que se inició tratamiento con fenitoina. Tomografía computarizada de cabeza nonnal. Al examen físico destacaba enflaquecimiento, deshidratación, alteraciones del tono muscular variando de hipotonía a hipertonía, conciencia alterada en grado variable, nistagmus bilateral, hipotermia, Pr. Arterial de $80 / 40 \mathrm{~mm} \mathrm{Hg}$., ruidos cardíacos apagados. Piel morena, con cicatriz pigmentada, persistencia del bronceado solar y melanoplaquias, adenopatía cervical derecha, dura, móvil de $4 \times 8 \mathrm{cms}$.

Exámenes de laboratorio: LCR; Transaminasas; Radiografía de abdomen simple; silla turca y edad ósea; Fondo de ojo y campimetría; $T_{3}, T_{4}, F S H$, LH, HGH y Astrup normales. Hemocultivos, urocultivos, cultivo de LCR, cultivo de Koch y baciloscopias negativas. Glicemia: $19 \mathrm{mg} \%$; Na: 123 
$\mathrm{meq} / \mathrm{lt} \mathrm{K}: 5.0 \mathrm{meq} / \mathrm{lt}$, Cortisol plasmático: $5,3 \mathrm{ug} / \mathrm{dl}$ (N: $15.2+2$ DS ug/d1). Cortisol post prueba de ACTH: $5.3 \mathrm{ug} / \mathrm{dl}$ (N: $20 \mathrm{ug} / \mathrm{d} 1$ ) PPD: $10 \mathrm{~mm}$; VHS: $27 \mathrm{~mm} / \mathrm{h}$; EEG: Compatible con encefalopatía hipoglicémica; la radiografia de tórax de. mostró un corazón en gota. Fenitoina sérica de $28.5 \mathrm{ug} / \mathrm{cc}$ (N: $10-20 \mathrm{ug} / \mathrm{cc}$ ). Con estos antecedentes, se diagnosticó enfermedad de Addison descompensada probablemente por una adenitis infecciosa cervical, siendo tratado con cloxacilina $100 \mathrm{mg} / \mathrm{kg} / \mathrm{día}$ por $10 \mathrm{dias;}$ Cortisona 30 $\mathrm{mgm}^{2} / \mathrm{dia} ; 9-\propto-$-fluorohidrocortisona $50 \mathrm{ug} / \mathrm{dia}$ y HIN prefiláctico por 6 meses. El paciente experimentó una espectacular mejoría, recuperando su rendimiento escolar, relaciones interpersonales y déficit de peso corporal. Por presentar una excreción aumentada de 17-OH corticoesteroides, de $7.2 \mathrm{mg} / \mathrm{m}^{2} / 24 \mathrm{Hrs}$. (N: $3.1 \pm 1.1 \mathrm{mgm}^{2} / 24$ ), se bajó la dosis de cortisol a 20 y luego a 12 $\mathrm{mg} / \mathrm{m}^{2} / \mathrm{d}$ ía, con lo cual se obtuvo normalización de los $17 \mathrm{OH}$-corticoesteroides y del ritmo de crecimiento (Figura 1 y Figura 2).
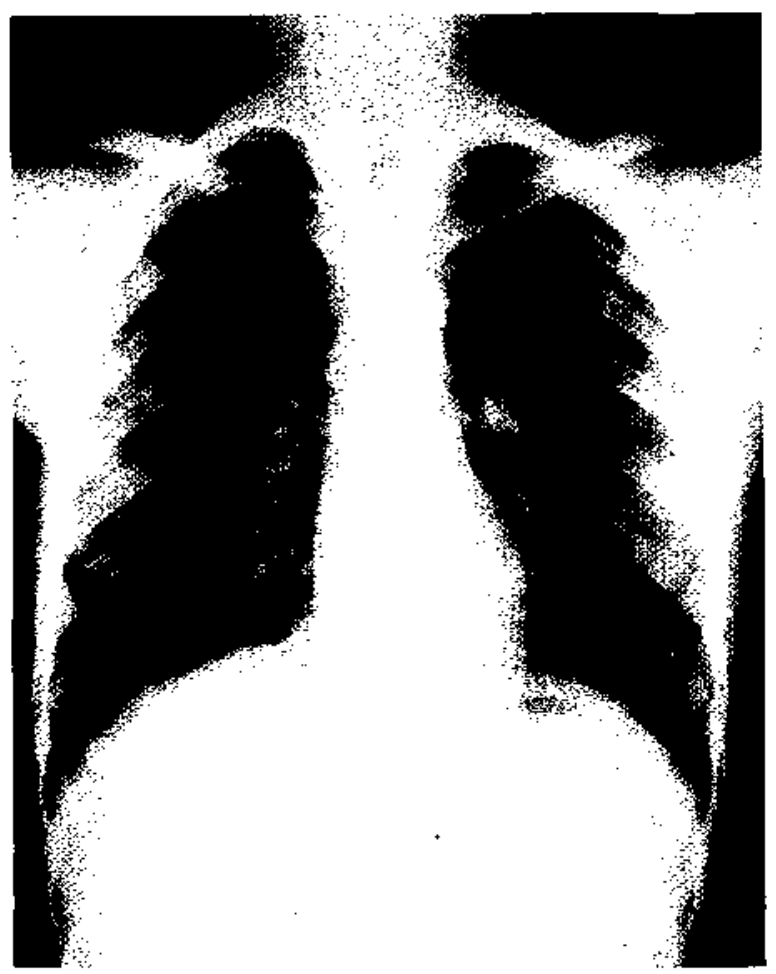

Figura 1.

Radiografía frontal de torax muestra una típica immagen de corazón en gota.

Por presentar una renina plasmática de 6.1 ug/cc/hr. (N: 1-2.5 ug/cc/hr) la $9-\infty-$ fluorihidrocortisona se aumentó de 50 a $100 \mathrm{ug} /$ día con lo cual la renina bajó a $5 \mathrm{ug} / \mathrm{cc} / \mathrm{hr}$.
ENFERMEDAD DE ADDISON : TRATAMIENTO Y EVOLUCION CLINICA

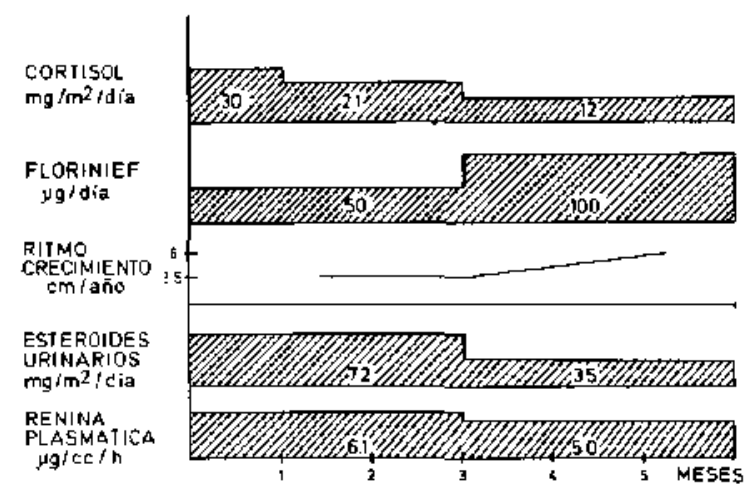

Figura 2.

Evolución y tratamiento del paciente con enfermedad de Addison.

\section{DISCUSION}

El hecho de tener un adolescente con un síndrome hipoglicémico, al que se asocian un EEG sugerente de encefalopatia, cambios de pigmentación de la piel, crisis de deshidratación por vómitos y diarreas después de intervenciones quirúrgicas o procesos infecciosos agudos, disminución del ta. maño cardíaco y alteraciones hidroelectrolíticas, hicieron sospechar una Enfermedad de Addison, que se confirmó por concentraciones séricas bajas de cortisol con falta de respuestas a la estimulación de ACTH y una extraordinaria recuperación con el tratamiento de reemplazo.

$\mathrm{La}$ insuficiencia suprarrenal crónica, puede ser de larga evolución antes de su descompensación o presentarse ésta sólo frente a situaciones de amenaza. En este paciente, transcurrió alrededor de un año antes de aparecer una alteración grave, habiendo presentado en el intertanto, un lento y progresivo compromiso del estado general, con agudizaciones transitorias por tensiones físicas y sólo se llegó al diagnóstico, a través del estudio de un síndrome hipoglicémico. Aunque la hipoglicemia es de baja frecuencia en la Enfermedad de Addison, su asociación con otros síntomas, hizo sospechar el diagnóstico, to que debería tenerse en cuenta, para la confirmación precoz de esta enfermedad, ya que influye en el pronóstico vital ${ }^{20}$.

Abreviaciones Usadas:

$\begin{array}{ll}\text { LCR } & \text { Líquido cefalorraquideo } \\ \mathrm{T}_{3} & \text { Triyodotironina } \\ \mathrm{T}_{4} & \text { Tetrayodotronina } \\ \text { FSH } & \text { Hormona Foliculoestimulante } \\ \text { HGH } & \text { Hormona de Crecimiento } \\ \text { ACTH } & \text { Hormona adrenocorticotrófica } \\ \text { EEG } & \text { Electroencefalograma }\end{array}$


Pensamos que la insuficiencia corticosupratrenal era de origen primario, porque no hubo respuesta a la prueba de ACTH y probablemente de etiología autoinmune, porque se descartó una Tuberculosis por la edad de presentación y las Radiografías( $(\mathbf{R x})$ de abdomen simple descartaron una hemorragia suprartenal. La sospecha de un mecanismo autoinmune como causa etiológica, obliga a estar alerta a la eventual asociación con otras patologías inmunológicas.

Es de interés hacer notar, que el caso que se presenta, es el primero en los 4 años de funcionamiento de nuestra Unidad de Endocrinología Infantil, concordando con la frecuencia baja descrita en la literatura.

La introducciôn a la terapéutica, del glucocorticoide fluorado (9- $x$-fluorohidrocortisona), que tiene gran acción mineralocorticoide y buena absorción por vía oral, fácil de administrar, ha permitido bajar las dosis de cortisol, lo que se traduce en un menor compromiso del crecimiento y desarroolo de estos pacientes.

Es conocido que existe un mecanismo de retro-alimentación negativo, entre mineralocorticoides y renina. Por lo tanto, ante un déficit de mineralocorticoides suprarrenales, existe una eleyación de la reninemia. Este mecanismo nos permite regular la dosis de 9- $\propto$ fluorohidrocortisona a través de la medición de la actividad de la renina plasmática.
En nuestro paciente la medición de actividad de renina plasmática abligó a subir la dosis $9-\propto$ fluorohidrocortisona al doble, lo cual permitió bajar aún más las dosis de cortisol, mejorando el ritmo de crecimiento.

Se presenta este caso clínico para recordar sus síntomas y enfatizar que la hipoglicemia aunque de baja frecuencia debe tenerse en cuenta en el diagnóstico diferencial para poder reconocer precozmente la enfermedad. Los cambios en la terapia mineralocorticoide y el control de la dosis por el laboratorio, ha permitido un mejor manejo del enfermo y un tratamiento a mantención más fácil de soportar.

\section{RESUMEN}

La enfermedad de Addison en el nifto, es poco corriente. Se presenta el caso de un nifo de 13 aitos con Enfermedad de Addison, cuyo diagnóstico se sospechó por presentar crisis hipoglicémicas y síntomas neuropsiquiátricos. El control del tratamiento con mineralocorticoides, se, efectuó midiendo la actividad de la renina plasmática. Se considera de interés conocer las diferentes formas de presentación de esta enfermedad, para evitar diagnósticos tardíos y se analiza las ventajas del corticoide fluorado, como terapia de reemplazo mineralocorticoidea.

\section{REFERENCIAS}

1 Wilkfins Lewson; "Endocrine Disorders" Third Edition.

${ }^{2}$ Coste-Castrerto. C. "En torno del primer caso de enfermedad de Addison descrito en Chile (1878)". Rev. Med. Chile. 106: 1034, 1978.

3 Costa-Cesaretto, C. "En torno del primer caso de enfermedad de Addison descrito en Chile (1878)". Rev, Med. Chile. 107; 675, 1979.

4 Swyer, G. "Addison's disease". British Medical Journal, 1979. 2, 25-26.

5 Parker, M.; Klein, I.; Fishman, L.M. and Levey, G.S. "Silent thyrotoxic Thyroiditis in Assoclation with Chronic Adrenocortical Insufficiency" Acch. Intern. Med. 140: 1108-1109, 1980.

'Riley, W.J.; Mac Laren, N, and Neufeld, M. "Adrenal auto Antibodies and Addison disease in insulin. Dependent diabetes Mellitus Joumal of Pediatrics. Vol. 97, 191-195. August 1980.

7 Bakdoud, Z,; Fraser, E.; Glover, L.; Lawson, W.G.; Fiser, R.H. and Elders J. "Rare occurrence of
Addison's disease and diabetes mellitus in children" Southem Medical Joumal. 713-715, 1977.

- Senior B. and Wolfsdorf, J.I. "Hypoglycemia in Children" Pediatric Clinies of North America. 6, pp 171-185, 1979.

- Winter, J.S.D. "Marginal comment: current approaches to the treatment of congenital adrenal hyperplasig" The Joumal of Pediatrics. Vol. 97, 81-82, 1980.

10 Spiniler, $\boldsymbol{H}$. and Vollor, $\boldsymbol{G}$. "Unsual acute neurological onset of Addison's disease" Medical Journal Australia 1: $280,1979$.

11 Rösler, A.: Levine, L.S.; Schneider, B.; Novograder, $M$. and New, M.I. "The interrelationship of sodium balance, plasma renin activity and acth in congenital adrenal hyperplasia". J. Clin. Endocrinol Metab. 45: $500-512,1977$.

12 Abodousky, N. y Jadresic, $A$. "Enfermedad de Addison en el niño" "Rev. Chil. de Ped. 33: 232-35, 1962. 